\title{
Vivir y enfrentar la integración/exclusión educativa en el nivel medio superior: Estudios de caso en jóvenes de San Luis Potosí, México
}

\author{
Vilchis Romero, Violeta; Arriaga Ornelas, José Luis \\ Vivir y enfrentar la integración/exclusión educativa en el nivel medio superior: Estudios de caso en jóvenes de \\ San Luis Potosí, México \\ Revista Educación, vol. 42, núm. 1, 2018 \\ Universidad de Costa Rica, Costa Rica \\ Disponible en: http://www.redalyc.org/articulo.oa?id=44051918007 \\ DOI: https://dx.doi.org/10.15517/revedu.v42i1.23249
}

Esta obra está bajo una Licencia Creative Commons Atribución-NoComercial-SinDerivar 3.0 Internacional. 


\title{
Vivir y enfrentar la integración/exclusión educativa en el nivel medio superior: Estudios de caso en jóvenes de San Luis Potosí, México
}

\author{
Living The Educational Integration/Exclusion in The Upper Middle Level: Case Studies in Young People from San \\ Luis Potosí, Mexico
}

Violeta Vilchis Romero [1]

Universidad Autónoma del Estado de México, México

DOI: https://dx.doi.org/10.15517/revedu.v42i1.23249

vio.antropologia@gmail.com

José Luis Arriaga Ornelas [2]

Universidad Autónoma del Estado de México, México

jlarriagao@gmail.com

Recepción: 17 Febrero 2016

Aprobación: 13 Julio 2017

\section{Resumen:}

Este artículo aborda la inclusión educativa a partir de las vivencias de jóvenes que poseen una discapacidad física y que han logrado cursar la educación media superior. El enfoque que se ofrece es cualitativo, con estudios de caso y mediante el empleo del método biográfico-narrativo (Moriña, 2010). Esta metodología permite “dar la voz" (Susinos y Parrilla, 2008) a quienes son capaces de señalar con precisión los elementos que impiden su inclusión en los entornos escolares en forma de barreras (Zarb, 1997), pero que también pueden señalar las ayudas que eventualmente les han permitido potenciarse como agentes (Bourdieu, 1997) en el escenario escolar. Los relatos de vida se recuperaron mediante trabajo de campo y fueron contextualizados etnográficamente, con la intención de obtener un panorama más amplio de la experiencia de los sujetos informantes, en el cual aparecen diversos actores que permiten o impiden su participación en la comunidad escolar. El objetivo fue visibilizar y escuchar a quienes regularmente permanecen invisibles y sin voz, para contribuir al incremento de su agencia. El artículo ofrece resultados sobre el tipo de posicionamiento que los sujetos de estudio adoptaron para conseguir su permanencia en las instituciones educativas, pero se pone en duda su real inclusión, pues se asume que esta no se logra, si por lo menos un individuo no se siente bienvenido en la escuela, o si su comunidad escolar no le proporciona múltiples y variadas oportunidades para aprender y participar (Ainscow, 2001).

Palabras Clave: inclusión educativa, ayudas, barreras, agencia, discapacidad física.

\section{ABstract:}

This article discusses inclusive education from the experiences of young people with a physical disability. The research method used is qualitative, since case studies and the biographical-narrative method is used (Moriña, 2010). This methodology allows give voice (Susinos and Parrilla, 2008) who are able to pinpoint the elements that prevent their inclusion in school environments as barriers (Zarb, 1997), and may also indicate the support that eventually they have allowed them to be strengthened as agents (Bourdieu, 1997). Life stories were collected during thr work field and were contextualized ethnographic, where different actors appear allowing or preventing its participation in the school community. The investigation was directed to identify the cultures, policies, and practices that these young people have been decisive in the educational process. The aim is to highlight and listen to those who remain invisible and silenced, to help increase your agency, if they do not include at least one individual does not feel welcome in the school and school community provides multiple and varied opportunities to learn and participate (Ainscow, 2001).

KEYWORDS: educational inclusion, high school, disability, support, agency.

\section{NotAS DE AUTOR}

[1] Egresada de la Facultad de Antropología de la Universidad Autónoma del Estado de México, Exbecaria de la Academia Mexicana de Ciencias para el programa "Verano de la Investigación" y actualmente coordinadora de la Casa de Cultura del municipio de Xalatlaco, Estado de México.

[2] Doctor en Ciencias Sociales, profesor de tiempo completo de la Facultad de Antropología de la Universidad Autónoma del Estado de México y líder del cuerpo académico "Patrones Culturales de las Relaciones Sociales" que cultiva la línea de investigación: Cultura, ambiente y educación. 


\section{INTRODUCCIÓN [3]}

El tema de la inclusión educativa ha sido básicamente materia de un discurso encaminado a señalar críticamente las condiciones estructurales, históricamente construidas, que resultan adversas a la inclusión de la diversidad en las aulas, lo cual termina constituyéndose en barreras sistémicas contra la inclusión educativa (Martínez, 2011). En dicho discurso y su reflexión implícita suele afirmarse que la causal de la exclusión se encuentra en los modelos educativos basados en el adiestramiento especializado, la formación experta, la eliminación de deficiencias (Barton, 2011) o el uso del código binario mejor/peor para regular la trayectoria del estudiantado (Luhmann y Schorr, 1990). Recientemente se ha presentado un fenómeno con tal discurso: "ha pasado de minoritario y periférico a ser indispensable en la retórica de las políticas oficiales, de la legislación y también de no pocos investigadores” (Susinos y Rodríguez-Hoyos, 2011, p. 16). Pero es de otro tema del que se hablará en este artículo, porque mientras el fenómeno del discurso tiene que ver con una reconsideración ética y una retórica "políticamente correcta", el que tiene que ver con la vida escolar más bien se ubica en el interés de las ciencias sociales, ocupadas en explicar cómo es que se conforman las construcciones simbólico-significativas que orientan la conducta, y cómo esta deriva en dinámicas dentro de las cuales hay muchas cosas en juego. Las que este trabajo decidió observar son tres: la voz de jóvenes que han vivido directamente los procesos de exclusión/inclusión en diferentes escuelas; las barreras y ayudas que los mismos sujetos protagonistas identifican como determinantes en su trayectoria escolar; y las condiciones que potencian o aminoran su agencia en el aula y en la comunidad escolar; es decir, su capacidad de agente: que tiene la posibilidad y la capacidad de empoderarse de las reglas y los recursos propios del entorno escolar.

En este trabajo se coincide con López-Melero al entender por "ayudas aquellos elementos del contexto educativo que contribuyen a que el alumnado esté incluido social y educativamente en las aulas. Las barreras, por el contrario, son los obstáculos que dificultan o limitan el aprendizaje, la participación y la convivencia en condiciones de equidad" (López-Melero, 2011, p. 42). Igualmente se recupera la esencia de la perspectiva de Echeita y Ainscow, para quienes "genéricamente, debemos entender como barreras, aquellas creencias y actitudes que las personas tienen respecto a este proceso y que se concretan en las culturas, las políticas y las prácticas escolares que individual y colectivamente tienen y aplican, y que al interactuar con las condiciones personales, sociales o culturales de determinados alumnos o grupos de alumnos - en el marco de las políticas y los recursos educativos existentes a nivel local, regional o nacional-, generan exclusión, marginación o fracaso escolar" (Echeita y Ainscow, 2011, p. 33).

No puede negarse la ascendencia de la antropología social en el interés que tiene este trabajo por recuperar y exponer la perspectiva de los actores, matizándola al documentar el contexto social, cultural y familiar que les rodea. Pero, al mismo tiempo, se hizo un esfuerzo por identificar, en sus relatos vivenciales, algunos indicios que hablen de cómo es que socialmente se (re)producen los mecanismos que les impiden participar, tomar acción y decidir dentro del aula o en la comunidad escolar. La finalidad de este artículo no es generalizar a partir de las opiniones y percepciones expresadas por sus casos de estudio, sino que a través de un análisis transversal y comparativo de sus historias escolares se quiere identificar aquellos elementos que resultaron determinantes en sus trayectorias educativas escolares (para integrarlos/excluirlos), porque la visibilidad de eso puede contribuir a que en las instituciones escolares se trabaje para generar condiciones de inclusión, más allá del discurso.

En términos metodológicos se procedió reconstruyendo la historia de tres jóvenes que han cursado la educación media superior y que viven en el estado de San Luis Potosí, México, mediante una interrogante general: ¿cuáles han sido las ayudas y las barreras que identifican y que les han permitido (o no) su inclusión en las instituciones educativas? El trabajo con el grupo de jóvenes se hizo mediante entrevistas semiestructuradas, efectuadas en distintos momentos. Posteriormente, y a partir de sus relatos, se buscó contextualizar los testimonios con entrevistas a sus padres y madres, amigos y amigas, pares de clase, docentes, y autoridades escolares. En este conjunto de datos se rastrearon los elementos constitutivos de una imagen 
estereotipada a la que se han tenido que enfrentar estos grupos de jóvenes a lo largo de su paso por distintos planteles escolares para mantenerse estudiando. Por último, se hizo una ponderación de aquellas condiciones y actores que potenciaron o disminuyeron la agencia de cada sujeto de estudio dentro del aula y la comunidad escolar.

\section{LA NECESIDAD DEL ACERCAMIENTO AL FENÓMENO}

En México el tema de la educación inclusiva fue precedido por la práctica de la educación especial y de la escuela de integración (Juárez, Comboni y Garnique, 2010; Romero y García, 2013). Con antecedentes particulares como la Escuela Nacional para Ciegos y su similar para sordos, que abrieron sus puertas en el último tercio del siglo XIX (Romero y García, 2013), la educación especial se consolidó en el siglo XX como la forma institucional para atender (con una concepción médico-asistencial) a alumnado con algún tipo de discapacidad. Sería hasta la década de los noventa del siglo XX cuando una reforma a la Ley General de Educación ordena promover en todo el país la integración de la niñez con discapacidad en los diferentes niveles educativos. Con una reforma a la Ley General de Educación se pretendía "asegurar que todos los niños y las niñas tengan la oportunidad de acceder a la escuela y de participar en procesos educativos que les permitan alcanzar los propósitos fundamentales de la educación básica y desarrollar todas sus potencialidades como seres humanos" (Soriano, García, Huesca y Rodríguez, 2007, p. 2-3).

A esta etapa se le conoce como proceso de integración educativa (Juárez et al., 2010; Romero y García, 2013). Políticamente se anunció en el año 1992, pero "en el plano operativo se inició de manera ordenada y sistemática a partir de 1998, con el Proyecto Nacional de Integración Educativa, mismo que se transformó en 2002 en el actual Programa Nacional para el Fortalecimiento de la Educación Especial y la Integración Educativa (PNFEEIE)" (Romero y García, 2013, p. 81). Pero los resultados fueron magros: "Después de 15 años de esta pretendida modernización de la educación, podemos aseverar que la escuela de la integración ha sido un fracaso, ya que no logró integrar a los niños y niñas con Necesidades Educativas Especiales, no permitió fortalecer el subsistema de educación especial, no logró alcanzar la meta de ofrecer educación para todos, no promovió la equidad ni suprimió la marginación" (Juárez et al., 2010, p. 69).

Al tiempo que esto ocurría en México, el tema de la inclusión educativa se tomó como bandera y agenda de las políticas educativas en las democracias liberales del mundo. Se constituyó explícitamente como agenda multilateral en la Conferencia Mundial celebrada en 1990 en Jomtien, Tailandia, con el planteamiento de una "Educación para todos" (EPT) y que tiene en la Declaración de Salamanca de 1994 su punto de partida definitivo (UNESCO, 1994). En dicho documento se reconoce que la escuela ordinaria debe y puede proporcionar una buena educación a todo el alumnado, independientemente de sus diferentes aptitudes.

Aunque, como dicen Escudero y Martínez, se ubica más en el plano ideológico y no fáctico, la educación inclusiva debe ser "entendida como un horizonte. La educación inclusiva -democrática, justa y equitativasigue justificando, sean cuales sean los tiempos actuales y por venir, la urgencia de concentrar fuerzas políticas y recursos, inteligencia organizativa y pedagógica, aportaciones de muchos agentes, todos los que puedan albergar todavía una conciencia acorde con el valor esencial de la educación, una educación buena de y para todas las personas" (Escudero y Martínez, 2001, p. 101).

En el caso específico de México, la política educativa hoy la dicta el Plan Nacional de Desarrollo 2013-2018 (PND), documento que propone, entre otras cosas, implementar políticas de Estado que “...garanticen el derecho a la educación de calidad para todos, el cual potencie el desarrollo de las capacidades y habilidades integrales de cada ciudadano, en los ámbitos intelectual, afectivo, artístico y deportivo, al tiempo que incluye los valores" (Gobierno de la República, 2013, párr. Eje México con Educación de Calidad). Debe resaltarse que el mismo documento advierte que aún existen deficiencias en la aplicación de políticas de equidad y calidad, por lo que "es urgente reducir las brechas de acceso a la educación, la cultura y conocimiento a través de una amplia perspectiva de inclusión que erradique toda forma de discriminación por condición 
física, social, étnica, de género, de creencias u orientación sexual". Sin embargo, cuando se trata de señalar cómo se lograría esto, el documento solo añade que para lograr la creación de verdaderos ambientes de aprendizaje se buscará "un fortalecimiento de la infraestructura, los servicios básicos y el equipamiento de las escuelas" (Gobierno de la República, 2013, p. 58-60).

No es el único documento oficial en el que las propuestas para generar escuelas inclusivas se reduce a los aspectos materiales. Son pocos los ejercicios que realmente recuperan los principios de la inclusión, basados en permitir el ejercicio del derecho a ser escuchado y a participar, a "formar parte de una comunidad escolar acogedora" (Susinos y Rodríguez-Hoyos, 2011, p. 18).

Uno de los problemas frecuentes en México en materia de inclusión educativa es que se pretende articular -sin que se sepa bien cómo- la educación en la diversidad con la educación de calidad. Y, entonces, ocurre que se termina hablando de esta última y se reduce el problema a la infraestructura, mobiliario, tecnología de vanguardia, y evaluación de docentes; queda, en un segundo plano, lo curricular y didáctico, lo cual solo conduce a "reproducir los esquemas y las prácticas que han predominado en nuestros sistemas desde la educación especial y educación compensatoria" (Moliner, Sales y Moliner, 2011, p. 15).

La idea de una educación de calidad, consignada como meta nacional en el PND, incluye un apartado para la "inclusión y equidad", en el que se señala: "para garantizar la inclusión y la equidad en el sistema educativo se deben ampliar las oportunidades de acceso a la educación, permanencia y avance en los estudios a todas las regiones y sectores de la población." Dicho de ese modo, pareciera que se resuelve el problema logrando que todos (independientemente de particularidades físicas, sociales, étnicas, de género, de creencias u orientación sexual) estén en la escuela. Pero, si eso llegara a ocurrir, ahí solo es el inicio de otra problemática: cuando ya la totalidad está en las aulas emerge el reto de garantizarles reconocimiento a "su capacidad y (que) se les garantice la oportunidad y el derecho de 'entrar en el juego', de participar, de decidir, de opinar y de tener el control de las cuestiones que le afectan vitalmente; de tener, en fin, su lugar y su voz" (Susinos y RodríguezHoyos, 2011, p. 18). La propuesta oficial, al respecto, hecha desde el propio PND, es impulsar la educación en valores, resaltando principalmente el respeto.

Así, ya ubicado el tema en el escenario de las aulas, conceptos como el de integración, inclusión y exclusión deben ser precisados. La exclusión, en términos generales, significa que dentro de un entorno hay grupos que tienen limitado el disfrute de las oportunidades económicas, sociales, culturales y políticas (ONU, 1998). Un mecanismo así afecta a grupos culturalmente definidos y se encuentra inmerso en las interacciones sociales (Banco Interamericano de Desarrollo, 2004). Por el otro lado, la integración e inclusión no deben confundirse, pues suponen presupuestos diferentes. En primera instancia, la palabra incluir deriva de la palabra integrar; mientras que la palabra integrar proviene del latín integrare, que significa el construir las partes en un todo, o hacer que algo o alguien forme parte de un todo. En tanto, la palabra inclusión, proviene del latín incluire, que quiere decir: "poner algo dentro de otra cosa o dentro de sus límites" (RAE, s. f., párr. 1). Para decirlo en palabras más sencillas, integrar significaría que toda persona que deba y quiera ir a la escuela pueda hacerlo; pero inclusión sería que ese conjunto diverso de sujetos terminara formando, cada quien a su manera, parte de la escuela de forma activa: contribuyendo a constituirla al tomar decisiones, hablar y actuar.

\section{¿Para qué una escuela inclusiva?}

Las metas generales de la inclusión educativa serían, en un primer nivel, disminuir y superar todo tipo de exclusión desde una perspectiva del derecho a la educación que garantice el acceso a una educación de calidad; $y$, en un segundo nivel, igualmente importante, que quienes integren los planteles educativos encuentren los mecanismos de participación y las condiciones para un aprendizaje exitoso. Este es un tema de derechos, no de altruismo, generosidad o caridad; y no solo atañe a las grandes fuerzas sociales, económicas y políticas, sino a instituciones y agentes políticos como los centros escolares y los profesorados (Escudero y Martínez, 2011). Como sugiere Arnaiz (2003), son tres los puntos en común que tienen las múltiples definiciones 
de la educación inclusiva: 1) Crear una sociedad más justa; 2) Crear un sistema educativo equitativo; y 3) Fomentar que las escuelas respondan a la diversidad estudiantil. Esto quiere decir que todos los individuos puedan ir a la escuela y que todos puedan tomar parte de una comunidad escolar.

Una interrogante que emerge de forma natural ante estos planteamientos es, si se necesitan escuelas especiales o las convencionales pueden operar de un modo inclusivo. Tal como lo señalan Juárez et al. (2010), históricamente la institución escolar ha pasado por distintos estadios y cumplido funciones específicas, según la época y el contexto. Se puede identificar, por ejemplo, la etapa elitista, durante la cual la escuela educaba a los hijos de las clases gobernantes; después puede nombrarse el rol social de control, en el que la escuela cumple el papel de institución preparadora de mano de obra y como medio para evitar la vagancia y la delincuencia juvenil. De la que se habla hoy es de la escuela como institución pública, es decir, como instancia que satisface el interés que tendrían todos los miembros de la sociedad en que las nuevas generaciones adquieran los saberes que les permitan desarrollarse.

¿Esa escuela pública con la que ahora se cuenta en México es integradora e inclusiva? No. En su diseño parecería integradora, pues el artículo tercero de la Constitución Política de los Estados Unidos Mexicanos (Congreso Constituyente-Estados Unidos Mexicanos, 1917, Art. 3) dispone que "todo ciudadano, todo niño, niña mexicano tienen derecho de recibir educación, sin distinciones sociales, religiosas, raciales y condición física". Sin embargo, de acuerdo con el diagnóstico elaborado por la UNESCO en el marco del seguimiento a la EPT, en nuestro país para el año 2010 había 7 millones de analfabetas; 1.4 millones de niños y niñas que no asisten a la escuela; más de 1 millón 324 mil de población mexicana con menos de cuatro años de estudio, y un número inestimable de personas analfabetas funcionales (UNESCO, 2010). La EPT (compromiso multilateral auspiciado por las Naciones Unidas) recomienda, en su Marco de Acción, que las escuelas deben acoger a toda la niñez, independientemente de sus condiciones físicas, intelectuales, emocionales, lingüísticas u otras, pues "las escuelas tienen que encontrar la manera de educar con éxito a todos los niños, incluidos aquellos con discapacidades graves...” (Conferencia de Salamanca. UNESCO, 1994, p. 59-60).

El crear o generar escuelas que integren a toda la población puede justificarse en diferentes dimensiones. Chavarría (2004) menciona tres: por motivos éticos, que obligan a brindar igualdad de oportunidades y no negar la educación a nadie, de acuerdo con sus necesidades y particularidades; por una razón pedagógica, porque la respuesta curricular debe ser amplia, variada y flexible; y en atención a la razón psicológica, que manifiesta la preocupación por los procesos de enseñanza y aprendizaje que el personal docente emplea hacia el alumnado y la cuestión de si estos son adecuados.

Pero integrar a todos y todas -ya se ha dicho- es el detonante de otra problemática: incluirles en la escuela, lo cual pasa por procesos muy complejos, como la adaptación al contexto social, la generación y seguimiento de procesos de inclusión para la totalidad de estudiantes en el marco de una comunidad educativa, o la generación de mecanismos de apoyo en la organización de adaptaciones curriculares. Dado que esta investigación se realizó con jóvenes que han cursado la educación media superior, hay que poner énfasis en que dicho nivel educativo agrava las dificultades para generar procesos de inclusión efectiva puesto que, al menos en principio, eso se contrapone al modelo actual de eficacia, individualismo y competencia de la educación media superior y superior en México. Este es uno de los principales retos a resolver, pues el modelo curricular está cimentado en el encargo de desarrollar en el estudiantado determinadas "competencias", definidas globalmente; en tanto, la educación media superior y superior abiertamente están diseñadas para la adquisición y especialización de competencias laborales que permitan desempeñar una actividad útil y productiva para el bienestar individual y social.

De este modo, cuando se habla de inclusión educativa no se pueden eludir los aspectos relacionados con la planeación, intervención y evaluación del proceso enseñanza-aprendizaje; las tareas de gestión y las estrategias que garanticen el acceso, la permanencia y la eficiencia terminal de jóvenes en los niveles de educación media superior y superior. Entonces, la transición que conduzca de la integración hacia la inclusión consiste en 
transformar la estructura del sistema escolar para atender el derecho a la educación de todo el alumnado, pero también potenciando su agencia al interior de los planteles: que tengan voz, participación y capacidad de decisión.

\section{CONOCER PARA PODER ACTUAR}

Como se dijo desde el principio, el objetivo de la investigación apuntó a dar la voz a quienes han experimentado procesos de integración/exclusión, para entender qué tipo de obstáculos son los que se deben librar y de qué manera han podido incrementar su agencia en los espacios escolares por los que han pasado. El recurso metodológico de la construcción (vivencia personal) de jóvenes con edades comprendidas entre 17 a 22 años de edad sirvió de fuente primaria, pero también se realizaron (para contextualizar lo dicho por los sujetos de estudio) entrevistas dirigidas a personal directivo, amistades, familiares, quienes han sido participes en este proceso de inclusión educativa. Los tres estudios de caso revisados corresponden a dos estudiantes con discapacidad visual y uno con discapacidad del habla. Los tres han cursado la educación media superior y viven en el estado de San Luís Potosí, México.

Mediante el proceder se buscó describir y explorar la historia de los sujetos de manera transversal, según propone Moriña para la realización de estudios de inclusión educativa: "la mejor manera de obtener datos es emplear el método de la investigación biográfica. ... Consiste en una entrevista desarrollada en profundidad en la que, mediante distintas cuestiones, se va invitando a los jóvenes a que vayan reconstruyendo sus historias de vida" (Moriña, 2010, p. 673).

Así, el enfoque cualitativo permitió indagar en las percepciones, en la subjetividad, desde la cual se calificó aquello que les afecta (Flick, 2007; Stake, 1999) en forma de limitante, barrera u obstáculo dentro de su desempeño escolar; esto incluye comportamientos de personal directivo, compañeros y compañeras y profesorado, o bien familiares, quienes también pueden presentarse por los sujetos informantes como apoyos o ayuda para lograr la inclusión educativa.

Se utilizaron (como medios propiciadores de la narración de cada sujeto de estudio) una auto-presentación, la entrevista biográfica y la entrevista focalizada (en ese orden). En la primera se consiguió una pequeña y breve descripción que el entrevistado hace de su persona; esta se puede considerar como un punto de partida que ofrece una visión general y coherente de sí mismo o de sí misma ante las demás personas. En la segunda, se pretendía que el sujeto reflexionara y rememorara su trayectoria vital; se trata de una entrevista amplia, en donde el sujeto entrevistado va recordando diferentes aspectos de su biografía (personal, escolar, familiar, amorosa, amistosa, etc.) que le propone quien le entrevista. Y, por último, la entrevista focalizada puede verse como una continuación de la técnica anterior, pero con mayor atención en la temática escolar. Como señala Flick (2007), se genera con ella un tipo de conocimiento específico, que es complementario al conocimiento más genérico obtenido en las entrevistas biográficas. Este autor lo denomina conocimiento episódico, y es de carácter argumentativo y explicativo por estar vinculado a circunstancias concretas (el tiempo, el espacio, personas, eventos, situaciones, vínculos). A cada informante se le pidió reconstruir su historia escolar a lo largo de los años con la intención de identificar las que las que consideran condiciones que posibilitaron permanecer en las distintas escuelas, además de los prejuicios u obstáculos que han tenido que superar para permanecer en el sistema educativo (aunque no siempre incluidos o incluidas). Fue importante, además, considerar el contexto social y cultural que les rodea y determina que cada proceso sea único e irrepetible.

Para el procesamiento de los datos, consistentes en narraciones de informantes, se retomó la propuesta de Bolívar, Domingo y Fernández (2001) de combinar el análisis narrativo con el análisis paradigmático. Así que, en los siguientes párrafos, se despliegan diversos datos de cada una de las trayectorias académicas del grupo de jóvenes que se entrevistó, tratando siempre de respetar su voz; y después se efectúa el ejercicio de generar inductivamente las categorías y códigos que permitieron realizar el análisis comparativo de la información 
recogida. En concreto, las categorías que se desglosan en el análisis de los datos obtenidos del trabajo de campo son:

- Tipo de discapacidad

- Datos socio - demográficos

- Relaciones sociales

- Barreras para la inclusión

- Satisfacciones /insatisfacciones

- Ayudas para la inclusión

- Expectativas

- Deseos

- Incidentes críticos

- Hábitos y estrategias de aprendizaje

Los datos que se presentan en este artículo proceden del análisis transversal de aquellos testimonios recogidos con relación con el ámbito escolar en las tres historias de vida del grupo de jóvenes, con el procedimiento ya descrito.

Los tres casos tienen en común trayectorias escolares caracterizadas por continuas situaciones adversas que impiden la estancia prolongada en una institución. Han tenido que enfrentarse y adaptarse a continuos cambios (sobre todo relacionados con los procesos de permanencia en un centro educativo, combinados con la asistencia a un aula de apoyo a la integración; el cambio de escuela en dos o incluso más ocasiones en una misma etapa educativa son cosas comunes). Esto no se entendería del todo si le mira al margen del diseño que tiene el sistema educativo mexicano, así que, a la par de presentar los casos, se harán algunas acotaciones relacionadas con ese diseño institucional.

CASO 1. Él tiene una discapacidad del habla. Actualmente cursa el 40 semestre de bachillerato, que es equivalente a 20 año de preparatoria, ${ }^{[4]}$ y vive en San Luis Potosí, en la capital del Estado. Tiene la edad de 19 años.

CASO 2. Ella tiene 17 años de edad, es una joven con discapacidad visual, vive en la ciudad de San Luis Potosí, lugar en que actualmente cursa el 6o semestre de bachillerato, equivalente al 3er grado de preparatoria.

CASO 3. Él es un joven con discapacidad visual, tiene la edad de 22 años. Tras concluir el nivel medio superior (o preparatoria) logró ingresar a la universidad y actualmente cursa el 40 semestre en la Facultad de Agronomía; es originario de Ciudad Valles, municipio perteneciente al Estado de San Luis Potosí. Para poder continuar sus estudios cambió de residencia hacia la capital potosina.

La trayectoria escolar de todo niño o niña en México debe iniciar con la educación preescolar; esta es obligatoria y atiende a menores de tres, cuatro y cinco años de edad. El objetivo en este nivel educativo consiste en ofrecerle a la niñez la oportunidad de desarrollar su creatividad, afianzar su seguridad afectiva y la confianza en sus capacidades, estimular su curiosidad y efectuar el trabajo en grupo. Es aquí donde se espera que adquieran una noción aparentemente sencilla, pero fundamental para estimular la escritura. En los casos 2 y 3 los sujetos informantes refieren haber ingresado a este nivel en una escuela regular/pública, a diferencia del caso 3 que, según cuenta, estuvo en un plantel privado:

"A los 5 años entré a preescolar; la maestra me trataba igual que a mis compañeros, pues ahí estaba mi hermana mayor y desde antes ya me conocía la maestra."

Pero antes de ingresar a preescolar, el caso 1 reporta haber estado en una escuela de educación especial, a la edad de dos años, lo cual -dice- le sirvió como apoyo al aprendizaje de la lengua de señas. Posteriormente, teniendo la edad de cuatro años, ingresa al preescolar y repite el tercer año "para reforzar sus conocimientos". También refiere que, al momento que se encontraba en el preescolar, recibió apoyo por parte del programa 
social Impulso Pedagógico Mexicano, lo que le generó cierta independencia y capacidad de socializar con sus iguales.

El segundo momento en la trayectoria estudiantil en México es la escuela primaria; obligatoria e impartida a partir de los seis años de edad. La duración de los estudios en este nivel es de seis años y, de acuerdo con el modelo educativo vigente, debe asegurar, en primer lugar, "el dominio de la lectura y la escritura, la formación matemática elemental y la destreza en la selección y el uso de la información. En la medida en que se cumplan con eficacia estas tareas, será posible atender otras funciones" (SEP, s.f., p. 7). En esta etapa educativa los tres casos recordaron una situación diferente a la anterior. El joven del caso 1 comenta que durante los seis años recibió apoyo por parte de una escuela especial de San Luis Potosí, conocida popularmente como IBIS (Instituto Bilingüe Intercultural de Sordos). Dicho apoyo le permitió - dice- tener cierta comunicación con sus compañeros y socializar. Pero a pesar de esto, él narra que:

"en la primaria recuerdo que al principio fue difícil, también por la comunicación, ya que no era muy efectiva; ahí aprendí a escribir un poco...".

En este caso el IBIS fungió como ayuda a la inclusión educativa; y el que hubiera un intérprete por parte de ese instituto, brindó al joven cierta confianza en el centro educativo, para una mejor comunicación tanto con docentes, como con sus propios compañeros y compañeras.

Por otro lado, en el caso 2, la primaria (los seis grados) los cursó en un colegio particular. En tanto que el caso 3 fue diferente: ingresó a un plantel regular/público a los seis años de edad, pero únicamente tuvo una estancia de seis meses.

"A la edad de 6 años entré a la primaria. Pero como el profe no me aplicaba los exámenes y al final del año me di cuenta que iba a reprobarme, decidí salirme y dejar de estudiar”.

Aunque, claro está, que esa decisión no la tomó propiamente él, sino en conjunto con su padre y madre, denota una clara denegación de agencia por parte de su profesora. Posteriormente, tras haber salido de ese plantel, su familia toma la decisión de enviarlo a una escuela especial en Ciudad Valles, municipio cercano a San Luis Potosí. En este lugar -dice- aprendió nociones de braille:

"Al año siguiente, mis papás me mandaron a estudiar a una escuela especial para personas discapacitadas, llamada "María Montessori”. Ahí estuve alrededor de siete meses, pero como estaba en un mismo salón donde había personas sordomudas decidí salirme de la escuela, pues no hablaba más que con la maestra”.

Fue hasta la edad de 11 años que nuevamente ingresó a la primaria, logrando concluirla a los 16 años:

“A los 11 años comencé desde primero de primaria, pero en un año hice primero y segundo".

El tercer momento en la trayectoria educativa, según el diseño del sistema educativo en México, es la escuela secundaria. Esta se cursa en tres años y está dirigida a la población que concluyó el nivel primaria. Los casos 1 y 2 estudiaron este nivel en escuelas regulares/públicas. El caso 1 comenta que a partir de esta etapa aprendió el lenguaje de señas:

"En IBIS aprendí señas; estaba con muchos sordos... Me siento muy bien con ellos, son mis amigos, platicamos y vamos a diferentes lugares".

De acuerdo con la Secretaría de Educación Pública (SEP), una de las prioridades del plan de estudios de la secundaria es asegurar que el estudiantado profundice y ejercite su competencia para utilizar el español en forma oral y escrita. Sin embargo, como lo refirió el caso 1, se le dificulta el español (lectura y escritura); y fue en el IBIS donde le brindan apoyo en la lectura y escritura. El personal directivo de este instituto dice:

...Este Instituto Bilingüe para personas sordas puede hacerlo con un diferente concepto de lo que tiene que ver con una cultura oyente; los oyentes manejan dos idiomas, por lo regular lo que es el español y otra lengua. Y entonces nosotros pensamos la oralización, la lengua de señas, a veces eso creen los oyentes pero nosotros tenemos otro concepto de conocer 
a las personas sordas, por ejemplo ¿Qué es ser Bilingüe? El uso de la lengua de señas, para un sordo la primera lengua es la lengua de señas, después la lectura y después la escritura, como si fuese un oyente, eso es ser Bilingüe, ese el concepto que nosotros manejamos la cultura sorda (Trabajo de campo, verano 2014).

De igual manera, las asignaturas impartidas en el nivel de secundaria tienen un objetivo integrativo; pero a diferencia de la primaria, en la secundaria ya se tiene como objetivo esencial el facilitar su incorporación productiva y flexible al mundo del trabajo. Es a partir de este nivel que se vuelve más notoria la deserción o abandono escolar, según el Instituto Nacional de Evaluación (INEE, 2015), con una tasa de 5.1\%; y en educación media superior de $14.3 \%$. A diferencia de los otros dos jóvenes, el caso 3 cuenta que estudió la secundaria en el Instituto Nacional para la Educación de los Adultos (INEA):

“Al entrar a la secundaria me dijeron que por la edad y por la vista no me aceptarían en una secundaria regular, que la única opción que tenía era la secundaria del INEA. Yo comencé a estudiar y en un año y medio terminé”.

El cuarto momento educativo en el diseño del sistema educativo mexicano corresponde a la educación media superior o preparatoria; esta se imparte después de la secundaria y la conforman tres subsistemas: el bachillerato general, que además incluye las modalidades de preparatoria abierta y educación media superior a distancia; el bachillerato tecnológico, modalidad de carácter bivalente que ofrece la carrera de técnico profesional, a la vez que prepara a las personas para la continuación de estudios del tipo superior; y la educación profesional técnica, que forma profesionales calificados y calificadas en diversas especialidades. Cada una se configura de manera diferente en cuanto a los objetivos que persiguen, la organización escolar, el currículo y la preparación general del estudiantado.

Respecto al tipo de bachillerato que cursa el grupo de jóvenes protagonistas del trabajo, el caso 1 comenta:

“Estoy en la preparatoria 'Jesús R. Alderete’; aprendí el lenguaje de señas con unos amigos, que se llaman Jazmín, Miriam, Marielena y Manolo, quien es maestro en IBIS”.

Por su parte el caso 2 recuerda:

Cuando entré a la Prepa... Creo que fue, ha sido, una de las etapas más difíciles en mi vida, porque cuando entré ... este... Mmm... Primero me cambiaron de turno; en la Secundaria estaba en la tarde y luego me cambié a la Prepa en la mañana. Y luego, pues, nunca, no sé, cómo que no encajé con los demás alumnos de la escuela donde me metieron mis papas; y en especial con las mujeres, como que así, no me querían. Entonces, no me hablaban, siempre estaba yo sola, o con una o dos amigas, pero todas las demás hablaban de mi, me decían de cosas, literalmente me hacían Bullying. Entonces ya hubo un momento en el que se aburrieron o se fastidiaron de que pues yo no les hacía caso ni nada, ni les decía nada de nada y me golpearon y entonces ya, bueno sí me golpearon súper feo (Trabajo de campo, verano 2014).

Luego agrega que, tras este episodio de violencia, sus padres la cambiaron de escuela. Al momento de ingresar a la nueva preparatoria -dice- recibe apoyo tanto de docentes, padre y madre, y una amiga de la secundaria. Los maestros le permiten llevar apuntes, sus padres le brindan la atención necesaria, ya que es la hija menor de tres hermanos, mientras que su amiga la apoya en las materias de Matemáticas y Física, porque se le dificultan.

La amiga con la que más me relacionó fue también su compañera en la secundaria.

“Creo que para mí la experiencia que me dejó así más marcada, la más bonita de mi vida académica, o todo, fue la Secundaria; creo que ahí fue donde conocí más personas, donde hice más amigos, donde a lo mejor me desatrampé un poquito, pero otra vez volví al camino y creo que la Secundaria siempre va quedar grabada siempre en mí. La Prepa fue algo así como más pasajero" (Trabajo de campo, verano 2014).

Por último, el caso 3 revela:

"Para entrar a la Prepa me dijeron que la única manera de hacerla era en Prepanet, (sistema de enseñanza en línea incorporado al Instituto Tecnológico y de Estudios Superiores de Monterrey), campus San Luis. Ahí hice la Prepa en dos años 5 meses y la Secundaria la había hecho en un año y medio". 
Él recuerda que tuvo que cursar la preparatoria sin estar en un aula, en un plantel escolarizado, debido "a sus condiciones". Posteriormente ingresa al nivel superior, que es el quinto nivel educativo, dedicado a formar profesionales en distintas áreas. Dice el caso 3:

"Cuando salí de la prepa estaba indeciso en estudiar para maestro o fitotecnia, ya que la escuela no me gusta y sólo lo hago porque me mandaron. Pero después de pensarlo mucho decidí estudiar Agronomía en la Universidad Autónoma de San Luis Potosí"

\section{Narra:}

El examen, el examen en la mañana... (tose) Fue el sábado en la mañana el examen de... el de conocimiento; en ese examen me mandaron a una persona del CIOAI Que me ayudara a, o sea que fuera conmigo ahí al examen, que estuviera de apoyo, pero pues yo preferí que una amiga, fuera y me leyera el examen ¿por qué? Porque pues ella me podía explicar más, porque ya me había echado la mano desde la prepa. Entonces, pues ya, fue el sábado el examen, estuvo... ¿Cristina? Si creo que si es Cristina. Ah, no, en ese tiempo fue Rocío la que estuvo... No sé cuál estuvo, si Rocío o Cristina. Bueno una de ellas estuvo y estuvo un ingeniero de ahí de la escuela, para estar checando que la chava que me estaba ayudando a mí no me dijera las preguntas y como el examen era en la mañana, me dieron media hora más de tiempo y pues si lo podía contestar bien. En la tarde en el examen ya en el psicométrico o CENEVAL como se le llame; en ese examen venían 110 preguntas de las cuales 30 eran imágenes, entonces pues yo traté de contestar, o sea yo contesté todo lo que venía sin imágenes ya faltando 10 minutos me dijeron "faltan 10 minutos" les dije que si me iban a dar la prórroga de media hora y fue cuando me dijeron que no me la iban a dar y pues ya contesté mi examen al ahí se va. O sea las imágenes como sea, era lo mismo (Trabajo de campo, verano 2014).

A pesar de recibir esa ayuda que comenta, también tiene muy presente lo que le dijeron tras los resultados de su examen de admisión:

Cuando iba a hacer mis trámites para el ingreso fui e hice los trámites normales; volví a pasar con la Dra. Rosa Elena entonces fue cuando ella me... Le dije: no, doctora, fíjese que sí quedé, quedé en el lugar número 5; entonces ya fue ahí cuando empezaron los conflictos; pues ella me dijo: no pues es que, mira, ¿cómo le vas a hacer cuando trabajes con microbiología?, que es ahora sí que organismos muy pequeños que muy apenas se alcanzan a distinguir; ¿cómo le vas a hacer cuando vayan al campo?; ¡ cómo le vas a hacer cuando tengan que hacer el estudio de algunas plantas? No pues yo le dije, bueno, mire, pues al campo yo soy de rancho, sé andar allá; los estudios de plantas van a estar más chavos examinándolos, les puedo preguntar la opiniones a ellos o sea ellos cómo ven las plantas, y de eso puedo sacar yo mis conclusiones. Le digo: aparte, lo demás con los profesores que usted me menciona pues eso ya se iría viendo, ya yo me voy adaptando a los profes o que me traten igual, nada más que cuando vayan escribiendo en el pizarrón pues que me vayan leyendo o algo así. Y pues la doctora dijo: no, bueno, pues, pues es que no sé; es qué sí hay profes que te van a ayudar y otros no. Entonces esta Rocío (sí era Rocío en ese tiempo, ya me acordé) le dijo que entonces los del CIOAI que iban a estar ahí que iban a hablar con los profes para capacitarlos, y ya fue como la doctora se quedó tranquila y pues yo entré ahí a lo que es la universidad (Trabajo de campo, verano 2014).

Con la intención de conocer las expectativas de los tres casos de estudio, una parte de las entrevistas se enfocó a pedirles que se visualizaran a futuro, que identificaran sus expectativas en los distintos rubros, empezando por lo académico. El caso 1 afirmó: "Yo quiero ser maestro de alumnos sordos o educación especial, o bien estudiar una ingeniería en la Universidad Politécnica de San Luis Potosí (que está cerca de su casa)". El caso 2 explicó: "Acabo de terminar la prepa, pienso entrar a la Universidad a la carrera de Administración Turística; voy a entrar a una escuela particular”. Y el caso 3, enlista lo que piensa hacer: "Terminar la carrera, trabajar en el rancho o en SAGARPA (Secretaría de Agricultura) y estudiar una maestría”.

\section{BARRERAS Y AYUDAS EN LOS RELATOS DE LOS SUJETOS INFORMANTES}

La estrategia de dar la voz a este grupo de jóvenes siempre tuvo la intención de conocer tanto barreras como ayudas que se pudieran haber convertido -según su propia percepción- en factores determinantes de su ingreso y permanencia en el sistema escolar. López-Melero (2011), define al menos tres tipos de barreras: 
Políticas (normativas contradictorias): La primera barrera que impide el aprendizaje y la participación de alumnado en las aulas y que está obstaculizando la construcción de una escuela pública sin exclusiones, son las contradicciones: por un lado, hay leyes que hablan de una educación para todos (UNESCO, 1990) y, simultáneamente, se permiten colegios de educación especial.

Culturales (conceptuales y actitudinales): La permanente actitud de clasificar y establecer normas discriminatorias entre el alumnado (etiquetaje); es la barrera que impide la inclusión. Es la cultura generalizada en el mundo de la educación de que hay dos tipos diferentes de alumnado: el, digamos, 'normal' y el 'especial' y, lógicamente, se tiene el convencimiento de que este último requiere modos y estrategias diferentes de enseñanza, de ahí que se hayan desarrollado distintas prácticas educativas desde la exclusión hasta la inclusión, pasando por la segregación y la integración.

Didácticas (enseñanza-aprendizaje): Procesos de enseñanza-aprendizaje que dificultan la construcción de una escuela sin exclusiones. (López-Melero, 2011, p. 143-145)

Respecto de las barreras políticas, México es miembro de la OCDE (Organización para la Cooperación y Desarrollo Económico) desde hace 22 años, por lo cual está obligado a atender sus recomendaciones. En materia de educación, la OCDE impulsó la prueba PISA (Programme for International Student Assessment) como el instrumento para medir lo que esta misma organización estima que debe aprender el estudiantado: recuperar y procesar información a través de la lectura, ser capaces de realizar deducciones con entes abstractos (como los números) y utilizar el conocimiento científico para tomar decisiones (OECD, 2016a; 2016b). De tal manera que las habilidades en lectura, matemáticas y ciencias es lo que en esencia mide dicha prueba. La aplicación de esta en los últimos años ha llevado a la OCDE a decir que "el desempeño de México se encuentra por debajo del promedio OCDE”. Y la autoridad educativa mexicana ha declarado que, precisamente, en atención a estos resultados consistentemente negativos es que se impulsó la reforma educativa del año 2013. $\mathrm{Al}$ respecto de la pertinencia de regir la política educativa por los resultados de la mencionada prueba PISA hay un debate, sobre todo por la prioridad que se da a ciertas áreas del conocimiento o asignaturas (DíazBarriga, 2006; Solano-Flores, Contreras-Niño y Backhoff-Escudero, 2006; Tiramonti, 2014; Vaca, 2005), lo cual se convierte en una barrera, sobre todo para sujetos como los de los casos de estudio, quienes no necesariamente pueden y deben aprender prioritariamente a escribir, leer y a razonar matemáticamente para una evaluación con un instrumento estandarizado.

El segundo de los tipos, las barreras culturales, es el que se puede profundizar a partir de los relatos recabados con los informantes, pues los otros dos tienen que ver con cosas que les trascienden o que no tienen la posibilidad de modificar. En cambio, lo que tienen que ver con su concepción de sí y los tipos de relación de estos sujetos con otros individuos y el entorno sí les permite identificar lo que tuvieron que enfrentar y los elementos en que se apoyaron. Sus testimonios en ese sentido se sistematizan en las Tablas 1, 2 y 3 , correspondientes con cada uno de los casos. 


\section{TABLA 1}

Tipos de barreas y ayudas. Caso 1

\begin{tabular}{|c|c|c|}
\hline & PERSONALES - CULTURALES & DOCENTES-AÚLICAS \\
\hline \multirow[t]{8}{*}{ AYUDAS } & Extroversión. & $\begin{array}{l}\text { Sus docentes de la preparatoria le apoyan en } \\
\text { el aula. }\end{array}$ \\
\hline & Anoro nor narte de aus nadre & Trabajando en equipo. \\
\hline & $\begin{array}{l}\text { Apoyo por parte de sus amigos y amigas, al } \\
\text { momento de comunicarse con sus docentes. }\end{array}$ & $\begin{array}{l}\text { Estando en Impulso ayudó a que tratara de ser } \\
\text { más independiente y aprendiera a socializar. }\end{array}$ \\
\hline & Perseverancia en los estudios. & Integración. \\
\hline & & Uso de la tecnología. \\
\hline & & $\begin{array}{l}\text { Estrategias de aprendizaje específicas, como el } \\
\text { apoyo en intérpretes. }\end{array}$ \\
\hline & & Creación de modelos específicos. \\
\hline & & $\begin{array}{l}\text { Está aprendiendo el lenguaje de señas en el } \\
\text { IBIS. }\end{array}$ \\
\hline \multirow[t]{3}{*}{ BARRERAS } & Extra edad. & Ritmos escolares. \\
\hline & Situación económica. & Falta de dominio de lengua escrita. \\
\hline & $\begin{array}{l}\text { Falta de dominio de la lengua de señas para } \\
\text { comunicarse con sus docentes. }\end{array}$ & \\
\hline
\end{tabular}

Nota: Elaboración propia con base en el trabajo de campo realizado en el verano de 2014.

\section{TABLA 2}

Tipos de barreas y ayudas. Caso 2

\begin{tabular}{lll}
\hline & PERSONALES - CULTURALES & CURRICULARES - DIDACTICAS \\
\hline AYUDAS & Extroversión. & Docentes de la preparatoria le apoyan en el aula. \\
& Considerable capacidad comunicativa. & Trabajando en equipo. \\
& Apoyo por parte de su amiga y su papá. & Integración. \\
& & $\begin{array}{l}\text { Estrategias de aprendizaje específicas, con el } \\
\text { apoyo de algunas personas. }\end{array}$ \\
\hline BARRERAS & Desconocimiento de temas. & Ritmos escolares. \\
& Timidez en el aula. & Falta de sistema braille en la escuela. \\
& & Adaptación de exámenes. \\
& Adaptación del espacio académico. \\
\hline
\end{tabular}

Nota: Elaboración propia con base en el trabajo de campo realizado en el verano de 2014. 
TABLA 3

Tipos de barreas y ayudas. Caso 3

\begin{tabular}{|c|c|c|}
\hline & PERSONALES - CULTURALES & CURRICULARES - DIDACTICAS \\
\hline \multirow[t]{6}{*}{ AYUDAS } & $\begin{array}{l}\text { Apoyo por parte de su padre, madre, } \\
\text { hermana y amiga. }\end{array}$ & $\begin{array}{l}\text { Docentes de la preparatoria le apoyan en el } \\
\text { aula. }\end{array}$ \\
\hline & Perseverancia y dedicación en los estudios. & Trabajando en equipo. \\
\hline & Comunicación estudiante-docente. & Integración. \\
\hline & & Uso de la tecnología (lap top) como apoyo. \\
\hline & & $\begin{array}{l}\text { Estrategias de aprendizaje específicas, como } \\
\text { la asistencia de amistades o auxiliares que } \\
\text { leyeran por él los materiales. }\end{array}$ \\
\hline & & Creación de modelos específicos. \\
\hline \multirow[t]{4}{*}{ BARRERAS } & Extra edad. & Ritmos escolares. \\
\hline & Situación económica. & Falta de dominio de lengua escrita. \\
\hline & & Adaptación de exámenes. \\
\hline & & Adaptación del espacio académico. \\
\hline
\end{tabular}

Nota: Elaboración propia con base en el trabajo de campo realizado en el verano de 2014

\section{ESCUCHANDO LA VOZ DE LOS AGENTES SILENCIADOS E INVISIBILIZADOS}

Recuérdese que metodológicamente se decidió observar los procesos que tienen que ver con la integración/ exclusión de los actores, poniendo especial atención en: su voz, las barreras y ayudas que han identificado, así como su agencia dentro de la comunidad escolar. Sus diferentes relatos muestran un panorama donde la integración resulta posible solo en la medida en que el sujeto y su grupo familiar realizan las acciones necesarias para incluirse en un sistema escolar que ofrece alternativas para casi todas las personas, sea mediante escuelas públicas, privadas o especiales. Sin embargo, esa integración no se traduce automáticamente en inclusión escolar, pues las experiencias al interior del aula van desde aquel dicho de que "el profe no me aplicaba los exámenes", hasta "no me hablaban, siempre estaba yo sola" o "solo hablaba con la maestra". Los episodios de violencia son el extremo de la no inclusión, pero hay muchos elementos más sutiles que contribuyen a la no integración, como aquellos consejos que, sobre todo el caso 3, escuchó reiteradamente, de que "no podría estudiar más que en INEA o en Prepanet".

Sobre todo es notoria la reiterada negación de agencia, que quizá no es exclusiva de jóvenes con las características de los casos estudiados, sino que se extiende a la comunidad estudiantil en general, por la falta de modelos escolares democráticos. Sin embargo, en el caso de los testimonios recabados, el que un estudiante que ha "ganado" su acceso a una escuela y al momento de irse a inscribir para iniciar sus cursos reciba una serie de observaciones excluyentes con la sencilla pregunta "¿cómo le vas a hacer cuando...?”, no son sino negaciones a su capacidad de actuar dentro del entorno escolar. Parte de los testimonios recabados (y no consignados por razones de espacio) narran la experiencia en grupo, cuando sus docentes le comentaban al caso 2: "es que nunca había tenido un caso como el tuyo", para explicar su desconocimiento de cómo actuar en un grupo diverso, compuesto por estudiantes que tienen formas distintas de aprender y medios diferentes para acceder a la clase y tomar parte en ella. Uno de los profesores entrevistados dijo:

Noté que a veces los temores y limitaciones las pone uno. Ellos hacen su esfuerzo a su manera; debemos acompañarlos en su proceso, adaptarnos a ellos y ser flexibles en los temas y contenidos para impartir lo importante de forma que dediquemos el tiempo necesario. A pesar de que al principio nos dieron unas pláticas sobre la inclusión no hubo comunicación con otros docentes, cada quien trabajó por su lado, sin compartir experiencias. Una labor que se enriquecería más al compartir se vuelve aislada y solitaria. ... Impartía clase en 3 grupos, mismo programa temático, misma distribución diaria de temas, sin embargo, 
diferente forma de impartir la materia. Puedo decir que se avanza más con los otros grupos, la causa es el hecho de leer lo que escribía en el pintarrón, dedicar un tiempo para explicar, revisar los apuntes de Chuy (refiriéndose a uno de nuestros casos de estudio), hacer pausas para dedicarme al grupo y otras para dedicarme a él. (Trabajo de campo, verano 2014)

Los principales obstáculos o limitaciones identificados en los testimonios de los tres casos no solo se refieren a aspectos físicos (como adecuación de instalaciones e implementación de tecnología que les permita acceder a los contendidos), sino fundamentalmente a la convivencia: a recibir ayuda de alguien, avanzar a un mismo ritmo todos, platicar, tener amigos, ser atendido por el profesorado en su particularidad (no especialmente) pero integrado a un grupo. Saber que, en el caso de los tres jóvenes que testimoniaron, sus limitaciones para continuar los estudios no solo tienen que ver con los contenidos curriculares (estandarizados y cuantificables), sino con ese aspecto de convivencia debe servir para entender qué hace falta ajustar para la generación de escuelas inclusivas.

En cuanto a las ayudas o apoyo que este grupo de informantes identifica como relevantes en su paso por las aulas destacan, en primer lugar, la de los amigos o amigas, quienes acompañan y auxilian; en segundo lugar está el de las instituciones que brindan atención especial, modelos específicos para el desempeño; en tercer lugar están los familiares, quienes aparecen en los relatos como actores que realizaron acciones sobre todo para conseguir la integración a los espacios educativos. En los testimonios llegan a identificarse estos rangos en función de la importancia mayor asignada a la vida en las aulas, dejando en segundo plano lo que tuvo que realizarse para acceder a estas mismas.

Los resultados obtenidos permiten sostener que, al menos en el Estado de San Luis Potosí, que es en donde han vivido y estudiado, se encuentra muy distante la inclusión educativa. No se puede sostener que esté imposibilitada la integración, que impide el acceso a opciones educativas; pero es evidente que al interior de los planteles existen múltiples prejuicios, estereotipos e imitantes de diversa índole, de carácter político y didáctico-curriculares que obstaculizan la formación de comunidades de convivencia y de aprendizaje, donde todas las personas tengan oportunidades equivalentes de participar, expresarse y decidir sobre las cuestiones que les interesan o afectan. Aunque la diferencia parezca semántica, integrar e incluir son cosas distintas, se trata de modelos diferentes de construir escuelas (en el sentido de hacerlas con el quehacer cotidiano). Como bien señalan Arnaiz (2003) y Moriña (2002), las diferencias se pueden representar como lo indica la siguiente Tabla 4.

TABLA 4

Diferencias entre escuela integradora y escuela inclusiva

\begin{tabular}{ll}
\hline \multicolumn{1}{c}{ ESCUELA INTEGRADORA } & \multicolumn{1}{c}{ ESCUELA INCLUSIVA } \\
\hline Centrada en el diagnóstico & $\begin{array}{l}\text { Centrada en la resolución de problemas de } \\
\text { colaboración }\end{array}$ \\
\hline $\begin{array}{l}\text { Dirigida a la educación especial (estudiantes con } \\
\text { necesidades especiales) }\end{array}$ & $\begin{array}{l}\text { Dirigida a la educación en general (todo el } \\
\text { alumnado) }\end{array}$ \\
\hline Basada en principios de igualdad y competición & $\begin{array}{l}\text { Basada en principios de equidad, cooperación y } \\
\text { solidaridad (valoración de las diferencias como } \\
\text { oportunidad de enriquecimiento de la sociedad) }\end{array}$ \\
\hline Exige transformaciones superficiales & $\begin{array}{l}\text { Exige rupturas en los sistemas (transformaciones } \\
\text { profundas) }\end{array}$ \\
\hline $\begin{array}{l}\text { Se centra en el alumnado (ubicándolo en programas } \\
\text { específicos) }\end{array}$ & Se centra en el aula (apoyo en el aula ordinaria) \\
\hline
\end{tabular}

Nota: Elaboración propia a partir de los conceptos de Arnaiz (2003) y Moriña (2002). 


\section{Conclusiones}

Una escuela inclusiva se construye a partir de la participación y los acuerdos de todos los agentes que en ella confluyen. En términos didácticos, la inclusión debe considerar el proceso de aprendizaje como un desarrollo de convivencia que se realiza a través del diálogo. Dar la voz al estudiantado (independientemente de sus condiciones particulares) es una vía pertinente para conocer lo que se debe realizar para concretar, en la práctica, la escuela inclusiva. Para gestar un modelo que potencie la educación inclusiva es necesario que todo el personal educativo, en especial el profesorado, tenga una visión y una actitud positiva acerca de la inclusión (Ferrer y Martínez, 2005), pero actualmente ello se encuentra limitado por una política pública que evalúa, cuantifica y sanciona a partir de criterios estandarizados, en los que ciertas áreas del conocimiento son priorizadas por corresponderse con un modelo político-económico supranacional.

Los casos de estudio en este trabajo son ejemplares en términos de una actitud de resistencia frente a las situaciones obstaculizadoras. Escuchando sus voces se puede comprender sus experiencias como una mirada hacia aulas que no necesariamente operan como un espacio público y de convivencia, sino que, más bien, reflejan una cultura, valores y finalidades de una sociedad "en la que aún está inscrita la imposibilidad de pensar adecuadamente la diferencia” (Arriaga, 2002, p. 93). En las escuelas inclusivas se precisa que el profesorado se entrelace con la comunidad estudiantil en un conjunto de interacciones que les permitan construir el conocimiento de manera compartida, formando una comunidad de convivencia y aprendizaje. Así que las instituciones educativas tienen el reto principal de ofrecer al desarrollo integral, para que el mismo alumnado se adapte y pueda ser "autónomo", sin dejar atrás el capacitar a las autoridades correspondientes del espacio académico para que puedan ofrecer ciertos servicios al estudiantado.

Cuando se escucha a jóvenes hablar de su procesos de integración/exclusión en diferentes instituciones educativas, queda claro que la educación no es solo cómo se le conceptúa, sino cómo se hace día a día (Arriaga y Ramírez, 2012). Ello puede entenderse como el hecho indudable de que quienes están inmersos en la actividad educativa (estudiantes, docentes, autoridades, familia) echan mano de un concepto de educación para racionalizar su actividad; este estructura su accionar, pero en el proceso de hacerlo no es ajeno a su capacidad de agente consciente, cognoscente y con capacidad de actuar. Son personas las que actúan y, por ende, sus prácticas estructuran lo que es la escuela y la educación. El resultado del día tras día en la escuela se convierte en el medio, proceso y resultado de las prácticas sociales. Son estas últimas las que dan cuerpo (espacial y temporalmente) a la escuela, esa donde los sujetos de estudio vivieron la dualidad integración/ exclusión. Son los sujetos/agentes los que actúan y hacen la educación.

Algo que los sujetos informantes no pudieron desarrollar plenamente en las distintas escuelas es su agencia, o sea su capacidad de apropiarse de las reglas y los recursos de los planteles educativos; pues si bien han podido matricularse en estos y de diversas formas mantenerse, gracias a la persistencia (propia y de sus familias), se les ha mantenido tan al margen que es magra su contribución a "hacer" esa escuela, en el sentido de contribuir a la constitución de una comunidad. Los diversos agentes que hoy están haciendo la escuela no son solo docentes y estudiantes, también debe incluirse a padres y madres de familia, autoridades, personal trabajador y hasta el propio currículo, el entorno social, entre otros factores. Todos estos agentes y su forma de pensar la escuela terminan estructurando lo que esta es. Así que tanto las barreras como las ayudas que se detectaron en el estudio se mueven en los planos personal, cultural, social, político, normativo, curricular y didáctico. En tanto que la permanencia de los sujetos de estudio en sus distintas escuelas obedece, principalmente, a su posicionamiento individual frente a las condiciones excluyentes que han enfrentado en los diferentes niveles educativos.

\section{REFERENCIAS}

Ainscow, M. (2001). Understanding the development of inclusive schools. London: Falmer Press. 
Arnaiz, P. (2003). Educación Inclusiva: Una escuela para todos. Málaga: Editorial Aljibe.

Arriaga, J. L. (2002). En la búsqueda del ser humano universal. Discapacidad y derechos humanos. México: CNDH.

Arriaga, J. L. y Ramírez I. (2012). Cómo piensan la universidad los que acuden a ella. Aproximaciones a la mentalidad de los estudiantes de la Universidad Autónoma del Estado de México. Espacios Públicos, 15(3), 150-173.

Barton, L. (2011). La investigación en la educación inclusiva y la difusión de la investigación sobre discapacidad. Revista Interuniversitaria de Formación del Profesorado, 70(25-1), 63-76.

Banco Interamericano de Desarrollo. (2004). Inclusión social y desarrollo económico en América Latina, Bogotá: BID.

Bolívar, A., Domingo, J. y Fernández, M. (2001). La investigación biográfica- narrativa en educación. Madrid: La Muralla.

Bourdieu, P. (1997). Razones prácticas. Sobre la teoría de la acción. Barcelona: Anagrama.

Chavarría, M. (2004). Educación en un mundo globalizado. México: Trillas.

Congreso Constituyente, Estados Unidos Méxicanos. (1917). Constitución Política de los Estados Unidos Mexicanos. México: Diario Oficial de la Federación. Recuperado de http://www.ordenjuridico.gob.mx/Constitucion/ cn16.pdf

Díaz-Barriga, Á. (2006). Las pruebas masivas. Análisis de sus diferencias técnicas. Revista Mexicana de Investigación Educativa, 11(29), 583-615.

Echeita, G. y Ainscow, M. (2011). La educación inclusiva como derecho. Marco de referencia y pautas de acción para el desarrollo de una revolución pendiente. Tejuelo: Revista de Didáctica de la Lengua y la Literatura,12, 26-46.

Escudero, J. M. y Martínez, B. (2011). Educación inclusiva y cambio escolar. Revista Iberoamericana de Educación, 55, 85-105.

Ferrer, G. y Martínez, S. (2005). Formació de les families en el marc de 1 \#escola inclusiva: Un repte per a les comunitats d \#aprenentatge. Revista Educar, 35, 71-85. Recuperado de http://www.redalyc.org/ $\mathrm{pdf} / 3421 / 342130824007 . \mathrm{pdf}$

Flick, U. (2007). Introducción a la investigación cualitativa (2da ed.). Madrid: Ediciones Morata.

Gobierno de la República. (2013). Plan Nacional de Desarrollo 2013-2018. Recuperado de http://pnd.gob.mx/

Instituto Nacional de Evaluación Educativa (INEE). (2015). Panorama Educativo de México. Indicadores del Sistema Educativo Nacional 2014. Educación básica y Media superior. México: INEE.

Juárez J. M., Comboni S. y Garnique, F. (2010). De la educación especial a la educación inclusiva. Argumentos, 23(62), 41-83.

López-Melero, M. (2011). Barreras que impiden la escuela inclusiva y algunas estrategias para construir una escuela sin exclusiones. Revista innovación educativa, 21, 37- 54.

Luhmann, N. y Schorr, K. (1990). Presupuestos estructurales de una pedagogía reformista. Análisis sociológicos de la pedagogía moderna. Revista de Educación, 291, 55-79.

Martínez, B. (2011). Luces y sombras de las medidas de atención a la diversidad en el camino de la inclusión educativa. Revista Interuniversitaria de Formación del Profesorado, 70(25,1), 165-183.

Moliner, O., Sales, M. y Moliner, L. (2011). Presentación. Revista Latinoamericana de Inclusión Educativa, 5(2), 15-19.

Moriña, A. (2002). El camino hacia la inclusión en España. Una revisión de las estadísticas de Educación Especial. Revista de Educación, 327, 395 - 414.

Moriña, A. (2010). Vulnerables al silencio. Historias escolares de jóvenes con discapacidad. Revista de Educación, 353 , 667-690. Recuperado de http://www.revistaeducacion.educacion.es/re353_25.html

OECD (2016a). Programme for International Student Assessment, Recuperado de http://www.oecd.org/pisa/

OECD (2016b). Programa para la evaluación internacional de alumnos (PISA) PISA-2015. Resultados, Recuperado de http://www.oecd.org/pisa/PISA-2015-Mexico-ESP.pdf

ONU (1998). Informe sobre desarrollo humano. Madrid: Mundi Prensa. 
Real Academia Española (RAE). (s. f.). Diccionario de la lengua española. Recuperado de http://dle.rae.es/? id=LFNhnwF

Romero, S. y García, I. (2013). Educación especial en México. Desafíos de la educación inclusiva. Revista Latinoamericana de Educación Inclusiva, 7(2), 77-91.

SEP. (s. f.). La estructura del sistema educativo mexicano. Recuperada de http://www.sep.gob.mx/work/models/sep1/ Resource/1447/1/images/sistemaedumex09_01.pdf.

Solano-Flores, G. Contreras-Niño, L. A. y Backhoff-Escudero, E. (2006). Traducción y adaptación de pruebas: Lecciones aprendidas y recomendaciones para países participantes en TIMSS, PISA y otras comparaciones internacionales. Revista electrónica de investigación educativa, 8(2), 1-21, Recuperado de http:// www.scielo.org.mx/scielo.php?script=sci_arttext\&pid=S1607-40412006000200003\&lng=es\&tlng=es

Soriano, C., García, J., Huesca, E. y Rodríguez, S. (2007). Integración educativa en México y Enciclomedia, ponencia presentada en el $7{ }^{\circ}$ Congreso Iberoamericano de Informática Educativa Especial, Córdoba, Argentina, 18-20 de agosto de 2007. Recuperado de http://capacidad.es/ciiee07/Mexico.pdf

Stake, R. (1999). Investigación con estudios de casos (2da ed.). Madrid: Ediciones Morata.

Susinos, T. y Rodriguez-Hoyos,C. (2011). La educación inclusiva hoy. Reconocer al otro y crear comunidad a través del diálogo y la participación. Revista Interuniversitaria de Promación del Profesorado, 25(1), 15-30.

Susinos, T. y Parrilla, A. (2008). Dar la voz en la investigación inclusiva. Debates sobre inclusión y exclusión desde un enfoque biográfico-narrativo. REICE Revista Electrónica Iberoamericana sobre calidad, eficacia y cambio en educación, 6(2), 157-171.

Tiramonti, G. (2014). Las pruebas PISA en América Latina. Resultados en contexto. Revista de la Asociación de Inspectores de Educación de España, 20, 1-24. Recuperado de https://avances.adide.org/index.php/ase/article/ view/96/95

UNESCO. (1994). Educación para todos. Recuperado de http://www.unesco.org/new/es/education/.

UNESCO. (2010). Llegar a los marginados. Informe de seguimiento de la EPT en el mundo. Paris: UNESCO.

Vaca, J. (2005). PISA sin prisa. CPU-e, Revista de Investigación Educativa, 1, 99-118, Recuperado de http:// www.uv.mx/cpue/num1/inves/pisa.htm\#

Zarb, G. (1997). Researching disabling barriers. En C. Barnes, y G. Mercer (Eds.), Doing disability research. Leeds: The disability press.

\section{Notas}

[3] Se extiende un agradecimiento por el apoyo de los profesores María R. Auces Flores, del Instituto de Ciencias Educativas, de la Universidad Autónoma de San Luis Potosí; B. Vega Martínez, de la Facultad de Psicologia de la Universidad Autónoma de San Luis Potosí; D.A. González Martínez y G. Jasso Padron, de la Facultad de Ciencias Sociales y Humanidades, de la Universidad Autónoma de San Luis Potosí, por su asesoramiento durante la instancia de investigación que se realizó con su participación dentro del programa Verano de la Ciencia en el año 2014.

[4] En México la estructura del sistema educativo está conformada por tres niveles: educación básica, media-superior y superior. El bachillerato o también conocida como preparatoria, conforma la educación medio superior y es a la que han logrado llegar los informantes.

\section{BY-NC-ND}

